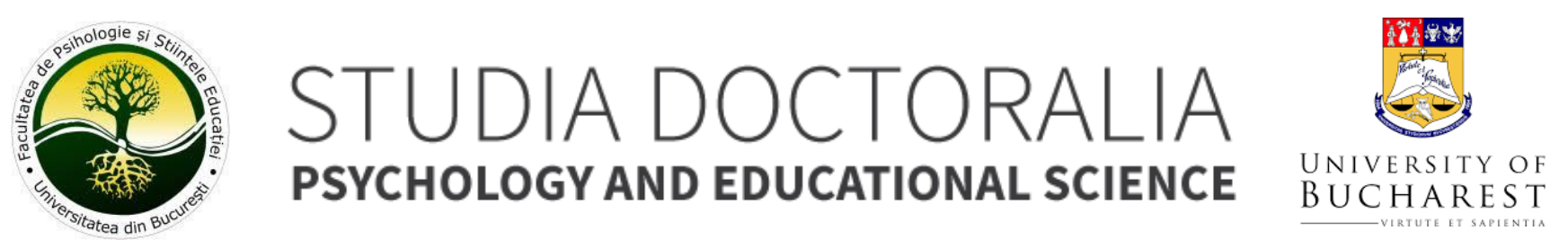

\title{
Social integration of children with and without ASD in their first school year
}

\author{
Alice Florentina Pruteanu \\ University of Bucharest
}

\section{ARTICLE INFO}

Article history:

Received 11-January-2020

Accepted 31-March-2020

Available online 01-May-2020

This article should be cited as: Pruteanu, A. F. (2020). Social integration of children with and without ASD in their first school year. Studia Doctoralia. Psychology and Educational Science, 11(1), 4-15.

This is an open access article under the CC BY license (http://creativecommons.org/licenses/by/4.0/).

University of Bucharest, Department of Psychology, 90 Panduri Av, Bucharest, RO.

Tel.: +40 (0) 31-425.34.45

E-mail address: alice.florentina.pruteanu@drd.unibuc.ro

\section{ABSTRACT}

The present research presents the results of a crosssectional study on the relationships among developmental level at the beggining of the first school year, interpersonal relationships, and social abilities at the end of the first school year, in children with and without ASD. The participants were 120 children, 60 diagnosed with ASD and 60 with typical development aged 6 to 7 years, $M=6.27$, AS $=.20$, of which 78 boys $(65 \%)$ and 42 girls $(35 \%)$. The instrument used for the measurement of developmental level was Portage Psychomotor Development Scale (Bluma et al., 1976), social skills were measured with 17 items of the Social Skills Rating System (SSRS) (Gresham \& Elliott, 1990), and the quality of relationships with others was measured with four items of the Sense of Relatedness Questionnaire (Furrer \& Skinner, 2003). Two hierarchical regression analyses were ran, with three steps each. The results showed that child-peer relationship and also childteacher relationship could diminish the effects of being diagnosed with ASD and also of developmental level on social skills. Practical implications were discussed. Our results support the importance of early interventions for children with ASD as a means to contribute to the developmental level of children with ASD, comparable with children without ASD.

Keywords: ASD, social skills, child-teacher realtionship, child-peer relationship, school inclusion

\section{INTRODUCTION}

\section{Children's transition to school}

The aim of the present study is to identify the relationships between the level of psychosomatic development at the beginning of the first year of school and the level of development of social skills at the end of the first year of school in children with and without autism spectrum disorders (ASD).

It is well known that the transition from kindergarten to school is a challenge for both children and parents, the transition being easier or harder depending on many 
individual and environmental variables. Equally well known is the tendency to include all the children in mainstream schools, regardless of their level of development or the nature of any disorders they face.

Burrell and Bubb (2000) believe that school success, both intellectually and socially, leads to a positive school path with beneficial implications for the whole process of adapting children to the school environment and requirements and to achieving significant progress in terms of their overall development. Some authors believe that the way children experience the transition from kindergarten to school not only influences their condition in the first months of school, but can have a long-term impact because the extent to which children feel and believe they cope successfully this transition will determine the nature of their subsequent school (and not only school) experiences (Fabian \& Dunlop, 2002; Dunlop \& Fabian, 2003).

Transition is considered an ecological concept (Bronfenbrenner, 1979) composed of a series of concentric structures (microsystems) joined together by a network (mesosystem) and influenced by society (macrosystem). All these interconnected systems - family, school, friends, community, society as a whole - accompany in one form or another the journey of children on their educational path.

Bronfenbrenner (1979) argued that an ecological transition occurs when a person's position in the ecological environment changes as a result of a change in the roles of the person, the environment, or both. Bronfenbrenner's model and principles are useful in understanding that the optimal development of the child depends on the quality of the mesosystem and its links with the micro- and macrosystem.

There are different ways to theorize childhood transitions. For example, van Gennep (1960) saw the transition as a "rite of passage" in which the uniform, the new colleagues, the new requirements mark the change of context. Campbell Clark (2000) saw the transition as a crossing of a border between two worlds, and Bourdieu (1991) saw it as a ritual of passing from one institution to another, in which it is necessary to transpose to school the symbolic capital gained at home. Elder (2001) presents the course of life theory that places children and families in the context of social structures, cultures and populations that influence them in time and space.

Bronfenbrenner's model shows that any child has the ability to cope with the transition process to a greater or a lesser extent. It also shows that the family and teachers can become active agents of change and support the successful transition of children, allowing them to somehow have control over the new situation.

Currently, the educational transition is defined as the process of changing the environment and establishing the relationships that the child achieves from one stage of education to another over time (Fabian \& Dunlop, 2002).
Transitions are characterized by phases of concentrated learning and accelerated development in a social context. Changing relationships, interactions, the environment, learning contexts and learning itself require accommodation efforts from children and their families (Fabian \& Dunlop, 2005).

Although most children eagerly await the school to begin and experience a smooth transition with the support of their parents to the preparatory class experience and the school atmosphere itself, there are also situations where children are not sufficiently prepared for this transition. This phenomenon occurs among children who previously did not attend any form of preschool education, those who do not have close parental support, those with developmental delays, developmental disorders, intellectual disabilities or other medical conditions.

For children with autism the transition to school is all the more difficult as their level of social interaction is lower, most teachers reporting that the child's social skills in school are more important than school abilities (Fontil \& Petrakos, 2015 ). The role of kindergarten is extremely important because there the child learns to interact with others and develops behavioral, emotional and social skills (Britto, 2012). At least as important is the role of the family, teachers and the school, which must be fully prepared to meet the special educational needs of the child with ASD. To these are added the individual particularities of each child, having to analyze in detail his strengths and weaknesses.

Marsh et al. (2017) conducted a meta-analysis on how children with autism transition to school, to create an overview of a series of issues such as: the extent to which children with ASD are ready to begin school, how parents and teachers experience the transition of children with ASD to school, the variables that influence the transition to school of children with ASD.

Regarding school readiness, despite the heterogeneity of the analyzed studies, the authors identified three studies whose results showed that children with ASD are less prepared for transition to school than typical children or those with intellectual disabilities due to lower social skills and precarious self-service. In terms of collaboration and communication between teachers and parents, although they are well and properly regulated by specific norms, in reality they do not occur. Teachers have been shown to be more concerned about the transition to school of children with ASD than those with other disorders, the practices used to facilitate the transition, although clear, are not customized, remaining at a general level, difficult to apply to children with different profiles. Regarding the individual factors of children with ASD, three identified studies analyzed the level of functioning of children and their emotional and social development. The results of these studies showed that at the end of the first year of school the 
language and communication skills of children with ASD improved, but the same improvements were not observed in socialization, cognitive development, sensory problems or behavior. Children with a lower level of symptom severity and a high level of communication at the beginning of the first year of school experienced more positive changes at the end of the first year of school.

Sparapani et al. (2016) developed a generalized tool to assess the active involvement of children in school activities, measuring emotion regulation, classroom participation, social connection, initiation of communication and flexibility. The authors reported that children with ASD have more difficulties in getting involved in the classroom, which are better addressed in normal classes than in special classes. At the same time, children with ASD have a lower level of emotional self-regulation, conversation initiation or generative language, managing to transfer their attention from one activity to another only in $50 \%$ of situations. The high level of social skills was positively associated with active involvement in all areas analyzed, while externalizing and repetitive behaviors were associated with less flexible behaviors in the classroom.

Eisenhower et al. (2015) analyzed the quality of relationships between teachers and students in association with the externalizing behavioral problems of children with ASD, noting that relationships between them remain low after the change of teachers (class), which leads to the idea that much of the children's behavior is responsible for the quality of these relationships. In the same direction, Prino et al. (2016) observed that the relationships between teachers and children with ASD are more difficult than those between teachers and children without ASD, with teachers reporting more frequent conflicts and less closeness.

Overall, the conclusions of the meta-analysis we referred to showed, firstly, that there are not enough longitudinal studies to show with certainty the success of the transition to school for children with ASD, and secondly that compared to children without ASD, those with ASD face a greater number of problems and challenges in school integration.

\section{School inclusion of children with ASD}

The inclusive approach argues that schools have a responsibility to help students overcome barriers to learning and that the best teachers are those who have the skills to help students do so. For this, the school must have functional strategies to address practical measures to facilitate the removal of barriers faced by students in their participation in education.

UNESCO defines inclusive education as a way of education adapted and individualized according to the needs of all children in age-equivalent groups and classes, in which there are children with very different needs, abilities and levels of competence. Schools must enroll all children, regardless of their physical, social, emotional, linguistic or other conditions. They also refer to children with disabilities or talents, street children and working children, children from distant or nomadic populations, children belonging to linguistic and ethnic minorities (Salamanca Declaration on Special Needs Education adopted at the World Conference on Access and Quality by UNESCO and the Spanish Ministry of Education, 7-10 June 1994) (UNESCO, 2004).

Based on these principles, more and more parents of children with special educational needs (SEN) are expressing their option to enroll their children in mainstream schools. Children with ASD are part of the category of children with SEN. As a result of the early diagnosis of autism spectrum disorders, the number of children with ASD is constantly increasing, and the number of children with ASD enrolled in mainstream schools is also increasing.

In Romania, children with special educational needs can enroll in school in the preparatory class if they have reached the age of eight, and at the explicit request of parents and on the basis of a school orientation certificate, they can enroll in the same way as other children from the age of six years. The school orientation certificate is issued by accredited institutions (CJRAE or CMBRAE) following the psychosomatic evaluation of children. The same school orientation certificate makes recommendations regarding the need for a support teacher (itinerant) or the permanent presence of an attendant (shadow).

Children with ASD have significant difficulties in social interactions, communication and behavior. For this reason, one of the biggest challenges for the child with ASD is enrolling in school and attending classes, the school being at the same time a source of learning skills, but also a source of challenge. Research on the effects of enrolling children with ASD in boarding schools is relatively scarce, and the data are relatively inconclusive, with the favorite topics of studies being bullying, anxiety, social isolation or loneliness (Chamberlain et al., 2007).

A study by Humphrey and Lewis (2008) showed that despite political efforts to regulate the inclusion of children with special educational needs (SEN), the process of facilitating learning and participation remains a complex and under-understood area of education. The notion of "special requirements" essentially refers to providing additional support to atypical children (Norwich \& Lewis, 2005). In reality, it starts from the assumption that if a child with ASD is fit, from a school point of view, then he will be able to integrate and cope with the context of mainstream school (Moore, 2007).

The difficulties that children with ASD experience in the area of social communication and interaction with others increase the risk that they become vulnerable to bullying or social isolation (Whitney et al., 1994). In addition, their preference for routine, predictability, and low sensory stimulation is at odds with the noisy, hectic, and chaotic 
environment in schools (Wing, 2007; Humphrey \& Lewis, 2008). Also, the specific cognitive profile and atypical learning style of these children is a challenge for teachers, who must be sufficiently well professionally prepared to cope with them (Jordan, 2005).

In recent years, the attention of specialists has turned to factors that can improve the educational environment to adapt to the requirements of children with ASD. Humphrey and Lewis (2008) identified a number of school-related factors involved in the successful inclusion of children with ASD, including differentiating homework and classroom activities, developing a predictable and organized environment, and placing children with TSA in classes of "good" and calm children, permanent consultation with the school psychologist on the specific problems of children with ASD. At the same time, correct and successful inclusion can be achieved by using strategies that involve other children who have been shown to have positive effects on both children with ASD and their peers (Dugan et al., 1995).

Children with ASD are not identical, so individual differences are additional factors that facilitate or hinder the process of child adaptation and school inclusion (TagerFlusberg \& Joseph, 2003). Children with ASD have different behavioral profiles than those of their peers without ASD, which are predictors of their (non) school adaptation (Frederickson \& Furnham, 2004).

Frederickson and Furnham (1998) suggested that the differences between children with ASD and those typically developed can be better understood in the light of Theory of Social Exchange (Thibaut \& Kelley, 1959). This theory explains the motivation to affiliate with others as being dependent on the costs and benefits of interactions with them, set at a minimum level of expectations. Frederickson and Furnham (2004) observed that in mainstream schools children with high levels of acceptance by others are those with high benefits (cooperation) and low costs (indiscipline,

\section{METHODOLOGY}

\section{Participants and procedure}

The participants of the study were 120 children aged 6 to 7 years, $M=6.27, A S=.20$, of which 78 boys $(65 \%)$ and 42 girls (35\%), 60 with ASD (50\%) and 60 without ASD (50\%).

Children with ASD were recruited from the researcher's therapy group. It should be mentioned that there are children diagnosed early (before the age of 3 ) with whom the researcher worked intensively for about four years. The inclusion criterion was to have reached the age of 6 at the date of the evaluation and to have received the agreement to enroll in the preparatory class from the specialized commission of CJRAE.

The 60 children with ASD come from localities located within the region of Moldova, being enrolled in schools in helplessness), on the other side there are children who experience social rejection. Frederickson and Furnham (2004) showed that there are significant differences between the behavioral profiles of accepted and socially rejected children, suggesting that social rejection is experienced by children who fail to provide minimal benefits (have traits in the benefits category), but have a high degree of traits in the cost category.

Taking into account the above, we want to give a unique nuance to this study by bringing together children with and without ASD, as they are otherwise enrolled and integrated into their classes. We believe that our research approach can contribute to the state of present knowledge, in the sense that it can build a sufficiently accurate profile of the child with ASD integrated in mainstream school. Moreover, we discuss the ability of children with ASD to successfully integrate with their peers without ASD, despite the differences between them and to adapt to life and school requirements. Our study also wants to emphasize the importance of early intervention in children with ASD, which gives them the opportunity to enroll in school at the same time as their peers without ASD, without having to postpone the start of formal education by a year or two.

Our intention is to test the association between the level of development at the beginning of school and the level of social skills at the end of the first school year in children with and without ASD, as well as the incremental role of children's relationships with the teacher and their colleagues in this equation. In this sense, we formulate the following hypothesis:

$\mathrm{H} 1$. The quality of interpersonal relationships within the school during the preparatory class brings an additional contribution in the development of social skills of students with and without ASD, above and beyond their sociodemographic characteristics and level of development at the beginning of the first school year.

Focșani, Brăila, Piatra Neamț, Buzău, Râmnicu Sărat, Tecuci, Tulcea, Odobești, and Panciu. For a greater equivalence of the groups, the 60 children without ASD were selected from the researcher's database, from the same localities as those with ASD. For example, for every child with ASD in Focșani, a child without TSA was also recruited from Focșani.

All 120 children were initially evaluated in the psychology office of the researcher, in January-February 2018, in order to prepare the mandatory psychosomatic evaluation file for enrollment in the first year of school (preparatory class). This further evaluation took place later in the CJRAE offices in March 2018 and resulted in all 120 children achieving a score that was the basis for obtaining the school orientation certificate. 
Prior to the initiation of this study, the children's parents were contacted and asked to agree to use the data from the children's assessment reports. They were given a description of the study, after which they were given informed consent forms and agreement to the processing of personal data forms, which were read, understood and signed. Moreover, the parents were asked to keep in touch

\section{Instruments}

The developmental level was measured with the Portage Psychomotor Development Scale (Bluma et al., 1976). The scale is part of the set of psychological instruments for the expertise and evaluation of children approved by the Romanian Government in 2002 and is one of the most used instruments in clinical practice in Romania, providing relevant and accurate information on the level of development of children aged one month to six years in five areas: self-service, cognitive development, motor development, language development and socialization.

The scale includes a series of items (88 for selfservice, 108 for cognitive development, 140 for motor development, 95 for language and 80 for socialization) in the form of statements that reflect those actions that the child must perform at a certain age. For each item a point is awarded if the described action is performed by the children most of the time. The points obtained for each domain are summed producing a global score for each development domain separately. This score is reported to the total number of items for the age of interest and thus the mental "age" or level of development of the child for each area is obtained. By dividing the arithmetic mean of the scores of all five domains to the chronological age of the child, the "global coefficient of development" (QD) is obtained from which the level of intellectual development (IQ) can be derived.

In the present study we used distinct scores for each area (in the form of mental age in years and months) to obtain a more accurate picture of the areas where the child still needs support, referring to them as: self-service, cognitive, motor, language, and socialization. Because our assessment was performed at the age of about 6 years of age, the scores closer to 6 reflect a higher level of

\section{RESULTS}

The mean scores and standard deviations are shown in Table 1, and the reliability coefficients and correlations between variables are shown in Table 2 . with the researcher in order to subsequently complete a set of questionnaires on the children's progress in the first year of school. All parents agreed to participate and were interested in the results of the study. It should also be mentioned that the 60 children with ASD continued the ABA therapy in the psychology office of the reasercher through an after school program, although at a less intense pace.

development. Examples of items: "Open a bottle of milk" (self-service), "Can tell the day and date of birth" (cognitive), "Jump and spin in one leg" (motor), "Tell simple jokes" (language) , "He chooses his friends" (socialization).

Social skills were measured with the Social Skills Rating System (SSRS) (Gresham \& Elliott, 1990). The scale includes 120 items, 40 for the parent, 40 for teacher, and 40 for child. In our study we used 10 items for parents and seven items for teachers, thus establishing the social skills reported by the parent (regarding the skills demonstrated by the child in out-of-school contexts) and the social skills reported by the teacher (regarding the skills demonstrated by the child in school contexts). The scales were completed by parents (mother) and teachers respectively. Scores were given on a three-step Likert scale where 1 - not at all or almost not at all, 2 - sometimes, 3 - very often or always. Examples of items: "Cooperate with family members on their own initiative" (social skills reported by the parent) or "Follow the teacher's instructions" (social skills reported by the teacher).

The quality of relationships with others was measured with the Sense of Relatedness Questionnaire (Furrer \& Skinner, 2003). The questionnaire includes eight items, four related to teacher and four related to colleagues. The items were adapted for the context of the present study and in relation to the children's level of understanding, being formulated in the form: "When I am with my teacher I feel accepted / unimportant / special / ignored", respectively: "When I am with my classmates I feel accepted / unimportant / special / ignored ". Items 2, 4, 6, 8 are scored in reverse. The answers are given on a five-step Likert scale where 1 - never and 5 - always. High scores reflect a closer relationship with the teacher / colleagues.

It is noted that the differences between children with ASD and those without ASD in all five areas of development are not very strong. 
Table 1. The mean scores and standard deviations $\left(N_{A S D}=60, N_{\text {nonASD }}=60\right)$

\begin{tabular}{rrrrrrrrrrr}
\hline & Group & Language & Cognitive & Social & Self-serv & Motor & ASPA & ASPR & RPE & RCC \\
\hline M & 1 & 5.12 & 5.18 & 5.37 & 5.16 & 5.82 & 16.6 & 12.7 & 15.2 & 13.7 \\
& 2 & 6.00 & 6.00 & 5.86 & 5.88 & 5.97 & 24.1 & 17.6 & 16.6 & 16.4 \\
\multirow{2}{*}{ AS } & 1 & .52 & .61 & .57 & .55 & .29 & 3.67 & 2.94 & 2.48 & 2.70 \\
& 2 & .01 & .01 & .27 & .31 & .12 & 5.28 & 3.20 & 2.34 & 2.51 \\
\hline
\end{tabular}

a. 1 - Children with ASD, 2 - Children without ASD

b. ASPA - Social skills reported by parents, ASPR - Social skills reported by teacher, RPE - Teacher-student relationships, RCC - Child-peer relationship

Table 2. Variable correlations and reliability coefficients $(\alpha)$

\begin{tabular}{|c|c|c|c|c|c|c|c|c|c|}
\hline & Language & Cognitive & Social & $\begin{array}{c}\text { Self- } \\
\text { serving }\end{array}$ & Motor & ASPA & ASPR & RPE & $\mathrm{RCC}$ \\
\hline Language & $(-)$ & & & & & & & & \\
\hline Cognitive & $.90^{* *}$ & $(-)$ & & & & & & & \\
\hline Social & $.68^{* *}$ & $.69^{* *}$ & $(-)$ & & & & & & \\
\hline Self-serving & $.55^{\star *}$ & $.55^{* *}$ & $.50^{* *}$ & $(-)$ & & & & & \\
\hline Motor & $.48^{* *}$ & $.55^{* *}$ & $.58^{* *}$ & $.33^{* *}$ & $(-)$ & & & & \\
\hline ASPA & $.60^{* *}$ & $.55^{* *}$ & $.55^{*}$ & $.55^{* *}$ & $.31^{* *}$ & (.77) & & & \\
\hline ASPR & $.64^{* *}$ & $.68^{* *}$ & $.65^{* *}$ & $.45^{* *}$ & $.38^{* *}$ & $.67^{* *}$ & (.74) & & \\
\hline RPE & $.32 *$ & $.28 *$ & $.28^{* *}$ & $.31^{* *}$ & .16 & $.42^{* *}$ & $.30^{* *}$ & (.71) & \\
\hline RCC & $.36^{* *}$ & $.33^{* *}$ & $.34^{* *}$ & $.27^{* *}$ & $.25^{* *}$ & $.41^{* *}$ & $.65^{* *}$ & .16 & (.72) \\
\hline
\end{tabular}

ASPA - Social skills reported by parents, ASPR - Social skills reported by teacher, RPE - Teacher-student relationship, RCC - Child-peer relationship

\section{Hypothesis testing}

$\mathrm{H} 1$. The quality of interpersonal relationships within the school during the preparatory class brings an additional contribution in the development of social skills of students with and without ASD, above and beyond their sociodemographic characteristics and level of development at the beginning of the first school year.

In order to test the established hypothesis, we used IBM SPSS 24 program (IBM Corp, 2013).

Two hierarchical regression analyzes were performed, having as predictors: in the first step the socio-demographic variables (gender, group, age), in the second step the level of the five areas of development, and in the third step teacher-student relationships and child-peers relationships, and as dependent variables, alternatively, the two models of perception of children's social skills, respectively those reported by parents and those reported by teachers. It is observed in Table 3 that the level of development in the five areas contributes incrementally to the prediction of social skills reported by parents, their effects being higher than the effects of sociodemographic factors. The results show that the sociodemographic factors included in step 1 are responsible for $43 \%$ of the variation of social skills, $F(3,116)$ $=28.67, p<.01$. Of the three sociodemographic factors analyzed, only the group predicts the level of social skills as they are perceived by parents (ASD diagnosis), $\beta=.65, \mathrm{t}$ $(120)=8.89, p<.01$. In step 2 , after introducing the level of development in the regression equation, it was observed that it explains another $8 \%$ of the variation of social skills, $F(5,111)=3.97, p<.01$. Of the five developmental factors, only two predict social skills perceived by parents, namely socialization, $\beta=.27, t(120)=2.62, p<.01$ and self-service, $\beta=.19, t(120)=2.04, p<.05$. After introducing the developmental factors in the regression equation, the effect of belonging to the group of children with ASD loses its intensity, $\beta=.38$, $t(120)=3.29, p<.01$. In step 3 , after introducing in the regression equation the teacher-student and child-peer relationships, it was observed that they bring a contribution of $6 \%$ in increasing the social skills reported by parents. Of the two types of relationships, the teacherstudent relationship has a higher effect, $\beta=.21, t(120)=$ $3.10, p<.01$, and the child-peer relationship has a slightly lower effect, $\beta=.14, t(120)=1.95, p<.05$. Also, there is a decrease in the effects of belonging to the group of children with ASD, $\beta=.31, t(120)=2.62, p<.01$ and of social development, $\beta=.21, t(120)=2.09, p<.05$, while the role of self-service becomes insignificant and the role of age becomes significant, $\beta=.14, t(120)=2.16, p<.05$. 
Table 3. Hierarchical regression analysis for socio-demographic variables, level of development, and interpersonal relationships as predictors of social skills reported by parents

\begin{tabular}{|c|c|c|c|c|c|c|c|c|c|c|c|c|c|c|c|}
\hline & \multicolumn{5}{|c|}{ Step 1} & \multicolumn{5}{|c|}{ Step 2} & \multicolumn{5}{|c|}{ Step 3} \\
\hline & B & ES & $\beta$ & $t$ & $p$ & B & ES & $\beta$ & $t$ & $p$ & B & ES & $\beta$ & $t$ & $p$ \\
\hline Gender & -.02 & .90 & -.01 & -.02 & .98 & .07 & .86 & .01 & .08 & .94 & .06 & .83 & .01 & .07 & .95 \\
\hline Group & 7.60 & .86 & .65 & 8.89 & .00 & 4.50 & 1.37 & .38 & 3.29 & .00 & 3.64 & 1.39 & .31 & 2.62 & .01 \\
\hline Age & 3.30 & 2.08 & .11 & 1.59 & .12 & 2.95 & 2.00 & .10 & 1.48 & .14 & 4.18 & 1.94 & .14 & 2.16 & .03 \\
\hline Language & & & & & & 1.20 & 1.81 & .12 & .66 & .51 & .79 & 1.74 & .08 & .46 & .65 \\
\hline Cognitive & & & & & & -.89 & 1.63 & -.09 & -.55 & .58 & -.59 & 1.55 & -.06 & -.38 & .71 \\
\hline Social & & & & & & 3.12 & 1.19 & .27 & 2.62 & .01 & 2.42 & 1.16 & .21 & 2.09 & .04 \\
\hline Self-serving & & & & & & 1.91 & .94 & .19 & 2.04 & .04 & 1.75 & .90 & .17 & 1.93 & .06 \\
\hline Motor & & & & & & -1.13 & 2.14 & -.05 & -.53 & .59 & -1.21 & 2.04 & -.05 & -.59 & .55 \\
\hline RPE & & & & & & & & & & & .50 & .16 & .21 & 3.10 & .00 \\
\hline $\mathrm{RCC}$ & & & & & & & & & & & .29 & .15 & .14 & 1.95 & .05 \\
\hline $\mathrm{R}^{2}$ & & & .43 & & & & & .51 & & & & & .57 & & \\
\hline$F_{\text {Change }}(\mathrm{df1}, \mathrm{df} 2)$ & & & $7(3$ & & & & & $7(5,11$ & & & & & $3(2,10$ & & \\
\hline$\Delta \mathrm{R}^{2}$ & & & & & & & & $.08^{* *}$ & & & & & $.06^{* *}$ & & \\
\hline
\end{tabular}

In Table 4 it is observed that the level of development in the five areas contributes incrementally to the prediction of social skills reported by teachers, their effects being higher than the effects of sociodemographic factors. The results show that the sociodemographic factors included in step 1 are responsible for $39 \%$ of the variation of social skills, $F$ $(3,116)=25.13, p<.01$. Of the three sociodemographic factors analyzed, only the group predicts the level of social skills as they are perceived by teachers, $\beta=.63, \mathrm{t}(120)=$ $8.39, p<.01$. In step 2, after introducing the level of development in the regression equation, it was observed that it explains another $20 \%$ of the variation of social skills, $F(5,111)=10.72, p<.01$. Of the five developmental factors, only two predict social skills perceived by teachers, namely cognitive development, $\beta=.44, \mathrm{t}(120)=2.90, p<.01$ and socialization, $\beta=.43, t(120)=2.52, p<.01$. After introducing the developmental factors in the regression equation, the effect of belonging to the group of children with ASD loses its intensity, $\beta=.39, t(120)=3.67, p<.01$. In step 3, after introducing in the regression equation the teacher-student and child-peer relationships, it was observed that they bring an additional $18 \%$ contribution in increasing the social skills reported by teachers. Of the two types of relationships, only the child-peer relationship has significant effects, $\beta=.41, \mathrm{t}$ $(120)=6.80, p<.01$. It is also noted that belonging to the group of children with ASD becomes insignificant, while the role of social development decreases in intensity, $\beta=.33, \mathrm{t}$ $(120)=4.05, p<.01$.

Table 4. Hierarchical regression analysis for socio-demographic variables, level of development, and interpersonal relationships as predictors of social skills reported by teachers

\begin{tabular}{|c|c|c|c|c|c|c|c|c|c|c|c|c|c|c|c|}
\hline & \multicolumn{5}{|c|}{ Step 1} & \multicolumn{5}{|c|}{ Step 2} & \multicolumn{5}{|c|}{ Step 3} \\
\hline & B & ES & $\beta$ & $\mathrm{t}$ & $p$ & B & ES & $\beta$ & $t$ & $p$ & B & ES & $\beta$ & $\mathrm{t}$ & $p$ \\
\hline Gender & -.03 & .62 & -.01 & -.04 & .97 & -.36 & .53 & -.04 & -.68 & .50 & -.11 & .44 & -.01 & -.25 & .80 \\
\hline Group & 4.90 & .58 & .63 & 8.39 & .00 & 3.06 & .83 & .39 & 3.67 & .00 & 1.34 & .75 & .17 & 1.79 & .08 \\
\hline Age & -.61 & 1.42 & -.03 & -.43 & .67 & -1.86 & 1.22 & -.10 & -1.53 & .13 & -.58 & 1.04 & -.03 & -.56 & .58 \\
\hline Language & & & & & & -1.57 & 1.10 & -.23 & -1.42 & .16 & -1.34 & .94 &.-20 & -1.44 & .15 \\
\hline Cognitive & & & & & & 2.87 & .99 & .44 & 2.90 & .01 & 3.03 & .84 & .46 & 3.63 & .00 \\
\hline Social & & & & & & 3.33 & .72 & .43 & 4.60 & .00 & 2.52 & .62 & .33 & 4.05 & .00 \\
\hline Self-serving & & & & & & -.68 & .57 & -.10 & -1.19 & .24 & -.39 & .49 & -.06 & -.80 & .43 \\
\hline Motor & & & & & & -1.56 & 1.30 & -.09 & -1.20 & .23 & -1.98 & 1.10 & -.12 & -1.81 & .07 \\
\hline RPE & & & & & & & & & & & .10 & .09 & .06 & 1.14 & .26 \\
\hline RCC & & & & & & & & & & & .55 & .08 & .41 & 6.80 & .00 \\
\hline $\mathrm{R}^{2}$ & \multicolumn{5}{|c|}{.39} & \multicolumn{5}{|c|}{.59} & \multicolumn{5}{|c|}{.77} \\
\hline$F_{\text {Change }}(d f 1, d f 2)$ & \multicolumn{5}{|c|}{$25.13(3,116)$} & \multicolumn{5}{|c|}{$\begin{array}{c}10.72(5,111) \\
20^{* *}\end{array}$} & \multicolumn{5}{|c|}{$\begin{array}{c}23.96(2,109) \\
.18^{* *}\end{array}$} \\
\hline
\end{tabular}




\section{DISCUSSION}

The purpose of this study was to analyze the role of children's developmental level in entering the preparatory class on the development of social skills at the end of the preparatory class, as well as the incremental effects of their relationships with teachers and colleagues. The study involved 120 children, 60 with ASD and 60 without ASD. The 60 children with ASD benefited from early diagnosis and intensive intervention from 3 to 6 years, so the differences between them and their colleagues without ASD when enrolling in the preparatory class were not very noticeable. Social skills were measured from two directions, from the perspective of the parent and from the perspective of the teacher. Parents' perception includes activities that the child performs in the family and in other contexts, different from school, and teachers' perception includes the child's activities in his class.

The results showed that the greatest role in the development of social skills is the inclusion in the group of children without ASD. The hierarchical regression analysis showed that in the case of social skills reported by parents, the greatest additional effect is brought by self-service and social development, which lead to diminishing the effects generated by the diagnosis of ASD. Moreover, the studentteacher and child-peer relationships bring with them an additional increase in cognitive skills, further diminishing the differences between children with and without ASD, but also those determined by the level of self-service development and socialization. Regarding the social skills reported by teachers, the greatest additional contribution is made by cognitive development and socialization, which diminish the differences between children with and without ASD, as well as child-peer relationships that manage to almost completely decrease the differences between children with and without ASD, and also diminishing the effects produced by social and cognitive development.

Our results highlight two aspects. Firstly, the importance of the role of interpersonal relationships within the school and the class of students, as well a certain level of development of the child when entering school, and secondly, the predilect areas on which parents and teachers focuse when evaluating children. Thus, for parents, social skills are based on the development of the child's level of self-service and socialization, to which is added the quality of relationships with teachers and colleagues, while for teachers, social skills are dependent on the level of cognitive development and the child's level of socialization, to which is added the quality of child-peer relationships.

In the view of parents, their child's social skills include the acquisition of an acceptable level of self-service to be able to fulfill some of their needs and desires and a sufficient social development for him to interact with others satisfactorily. In the view of teachers, the child's social skills include a certain level of cognitive development and secondly a certain level of social development.

Knowing the retention of some teachers when it comes to class integration of a child who deviates from normal in one form or another and especially when he has to receive in his class a child with ASD, it becomes explicable that the cognitive development of the child to be a major concern for teachers. For the teacher, the child's cognitive development is the main goal and the essential purpose of his teaching activity. Starting from a cognitive level as close as possible to that of the normal child, the child with autism thus has similar premises for a good school adaptation and for a proper development of social skills. In parallel with the level of cognitive development, social development also facilitates the teacher's work with his students. If the child's socialization was started early and he seems eager to interact with his new colleagues, then the work done by the teacher to build class cohesion will be greatly diminished.

In our study, socialization is of particular importance in the vision of parents. We mention here that the parents of children with ASD are part of the category of those who consider that intensive therapy is not only necessary, but welcome for the proper development of their children. In this regard, these parents have invested significant resources to increase the level of socialization of their children and the mere fact that these children have received the consent of a specialized commission (CJRAE) to enroll in a boarding school shows that they have the prerequisites for good adaptation to school.

In our study we wanted to capture those dimensions that contribute more to the development of social skills and thus to the school adaptation of children. Thus, a higher level of cognitive and social development will contribute more to school adaptation, according to teachers, to which is added the quality of child-peer relationships, and a higher level of self-service and socialization will contribute more to adaptation to school in the view of parents, to which are added both the student-teacher and the child-peer relationships.

The social skills of a six-year-old cover a wide range of actions such as greeting, asking questions, answering questions, asking permission to participate in games or other activities. In children with autism, social initiations are lower than social responses. Sometimes their social initiation actions are unclear or inappropriate to the context. Social comprehension is also poor. This includes understanding social norms, engaging in behaviors appropriate to certain situations, interpreting social cues.

As a result of the involvement of children with ASD in intensive therapeutic programs, the level of social development can be improved so that they can meet the requirements of the school and end up acquiring social skills similar to those of children without ASD. Regarding the development of autonomy, at the beginning of the 
preparatory class children with or without ASD are at different levels. The degree of independence of children depends on many factors. On the one hand, intrapersonal factors, the child's psycho-physiological characteristics or temperamental type intervene, on the other hand, family and environmental factors intervene. The way in which the child is taught to perform actions that would lead to the satisfaction of his needs and desires strongly imprints his level of independence. The child who is allowed to experience various activities has all the chances to become much more adepted at performing them than the child who is blocked. Kindergarten years also have a potentiating effect on a child's autonomy.

With regard to self-care activities, we can mention those practical skills needed to perform daily self-care tasks, such as dressing and undressing, feeding, maintaining hygiene, using the toilet, preparing the backpack. Among children with autism, despite the fact that they are able to perform these activities, they may not actually want to perform them. The level of "compliance" in performing these actions is a predictor of the child's overall functionality (Gillham et al., 2000) and an essential indicator of his successful adaptation to the world (Liss et al., 2001). For this reason, in the parents' reports, self-care skills are one of the starting points for the development of the child's social skills.

The early intervention programs that benefited children with ASD participating in this study aimed (among other objectives) to prepare children for the first year of school, so that the differences between them and their peers without ASD to fade as much as possible. At the same time, this approach has contributed to building the child's selfconfidence, the belief that he can cope with the demands of school just like other children, which implicitly leads to facilitating adaptation to the new lifestyle, school life, but also to acquiring stronger social skills in that they can be considered at the same level as other children.

The results obtained by us emphasize the effects of the connections that are formed among children in their first year of school on their good adaptation and on the development of social skills. The development of social skills is deeply dependent on child-peer and teacher-student relationships.

It is important to note that all children with ASD in the present study are highly functional due to the early therapeutic programs they participated in, and this contributes to reducing the differences between them and their colleagues without ASD. Also, none of the children with ASD participating in the study had a companion (shadow), being "on their own" in all activities and interactions in the classroom. The absence of a shadow contributes to the efforts to gain the child's autonomy (where possible), "forcing" the process of socialization. Once included in the class of typical children, the child with ASD is somehow forced to enter their game, to comply like everyone else with all the rules, to accept like everyone else that there are activities in which he can participate successfully, but also activities that exceed his actual possibilities. Integration means more than acceptance, it essentially means learning who you really are and how much you can do. Moreover, it means that efforts are needed to reach and exceed the potential of the moment. Parents of children with ASD, but also parents of children without ASD, have understood that there are differences among children, but that they can become insignificant when there is mutual understanding and support from each direction.

The good relations between colleagues have as a starting point the very acceptance of the differences that children involuntarily notice, but also the attitudes of teachers and parents towards these differences. In general, children with ASD, even the highly functional ones, have difficulties in developing interpersonal relationships with their peers, on the one hand because they fail to get actively and persistently involved in cooperative activities and on the other hand because they are restrictive in terms of interactions with others. Children with ASD can be so focused on a task that they cannot focus on an event that overlaps with their task. This detail can annoy children without ASD who are unaware of these issues. But if the latter are explained how children with ASD "work", interactions become possible and even constructive.

The teacher's role is to facilitate these interactions, to group the children so that everyone can offer what they can do best. In a group project, the child with ASD can perform repetitive, meticulous tasks that would bore a child without ASD, but which are absolutely necessary to complete the task. This approach must be initiated by the teacher by allocating group tasks according to what the child can do best. After enough practice in such actions, children will gain the belief that they can complete tasks and that they are indispensable in their team. This builds self-efficacy, which then leads to confidence in one's own abilities and a desire to perform increasingly difficult tasks. In addition, the feeling of belonging to the group is built, which gives the child an identity. He belongs to a class of students who accept him, in which his contribution is needed, and his absence would be felt by both the teacher and his colleagues.

The teacher's task is not an easy one, but in a class of students, even if there are no children with ASD, there are extremely different children, with different learning rhythms, different behavioral patterns, different temperaments, different levels of development and with different skills. Through the good knowledge of his students, the teacher can contribute directly to the development of children's social skills, but also indirectly, by facilitating the construction of quality relationships among students.

In essence, the acceptance of diversity is the key element of interpersonal relationships, and it is trained from early childhood. Later, in kindergarten and school, children will know how to react when collaborating with their different 
classmates. When we refer to differences, we do not necessarily say ASD, but there may be cultural, ethnic, developmental, environmental differences. There are often in the classes of students children who do not have a specific diagnosis, but who do not meet the school requirements, there are children with learning disabilities or who come from disadvantaged backgrounds that do not support them in their school career. All of these children are different and each needs to be accepted and understood. Moreover, everyone needs to be naturally integrated into their group of peers, by emphasizing their qualities and engaging in meaningful activities, from which to understand that their contribution is valuable and that he himself is valuable.

In general, existing studies have focused on identifying the negative effects of fragile interpersonal relationships of children with ASD and not on the positive effects of possible quality interpersonal relationships. We consider that our study brings a note of novelty in this direction, by the fact that we wanted to capture the extent to which children's adaptation to school environment and the acquisition of social skills is dependent on the quality of their relationships with teachers and peers, but also on their initial level of development.

Kelly et al. (2008) conducted a study in which they investigated the role of family relationships and relationships with peers in the manifestation of anxiety and depression symptoms. The study involved 322 children (answers were provided by parents) with and without ASD. The authors found that the main causes of anxiety and depression are family conflicts and only in the second run relationships with peers. Bauminger and Kasari (2000) found that unlike typical children, those with ASD report poorer interpersonal relationships, and Little (2002) found that children with ASD are more likely to be marginalized and abused in school, which prevents the acquisition of adequate social skills.

Regarding the integration of children with ASD and the role of interpersonal relationships, Watkins et al. (2015) conducted a literature review in which they analyzed 14 studies on interventions based on the involvement of peers in order to facilitate school integration of children with ASD. This study highlighted social validity as an essential measure of peer-based interventions, so as all those involved, such as teachers, peers, children with ASD, report positive results and experiences. This type of intervention tends to be implemented more and more frequently (Kennedy, 2002). Social validity has been reported or demonstrated in most studies (Hughes et al., 2013; Katz \& Girolametto, 2013; Koegel et al., 2013). In addition, normative data comparing the levels of social interaction of children with ASD with those of children without ASD and direct observations of social behaviors suggested that peer involvement significantly increases the social interactions of children with ASD to levels comparable to those of children without ASD. These results show that the contribution of peers combined with the contribution of teachers contributes to the development of social skills of children with ASD. The study mentioned above highlights the characteristics of the interactions between students with and without ASD that lead to the development of social skills of both categories of children, including proximity, prompting and reinforcement (involuntary, in natural interactions between peers), mutual imitation, modeling initiation actions.

It should be mentioned that in addition to the natural interactions between children, teachers' interventions are extremely useful, such as providing additional work materials (toys, drawings, worksheets, concrete objects), initiating social games, dialogue on social issues, promoting team activities, conducting group projects.

\section{Practical implications}

Our results can go in two pragmatic directions. The first direction refers to the early intervention addressed to children with ASD. We strongly support this type of intervention, starting from the personal experience gained during decades of effective practice. First, we propose early diagnosis of children with any form of autism. Many of the children who are at risk of being diagnosed with ASD and who benefit from adequate early intervention tend to achieve more skills and to increase their overall developmental state when enrolling in school, comparable to children with typical development. Following diagnosis, we support the inclusion of children with ASD in personalized intervention programs that facilitate the natural course of their development, comparable to the course of other children.

The second direction of our results consists in the permanent analysis of the quality of the relationships in which the students are involved in the school, more precisely in their class, by meaningful interactions with their teacher and peers. We believe that it is imperative that teachers receive additional training courses to learn how to manage and meet the needs of children with atypical development, whether they are diagnosed or not. It is known that in school classes there are children, few in number, who have a clear diagnosis (ASD, ADHD, dyslexia, dysgraphia, etc.), but there are also a large number of undiagnosed children who may have symptoms specific to certain disorders such as global developmental delay, learning disorder, conduct problems. To these are added the diversity of children in general and the different pace of development, learning, concentration, homework, participation in individual or group activities.

To meet these real needs, teachers must first know the specifics of these disorders and ways of manifestation, and then master clear methods of managing situations that may arise in the classroom. For a teacher who teaches 25-30 students, ten of whom have atypical development, it becomes a huge challenge to maintain a balance and teach each one in an appropriate way. Although the preparatory 
class is a "training" class, for the teacher it is a special effort to know, understand and interpret the specifics of each child and to act according to his characteristics. Therefore, we support the need to offer specialized courses for teachers in which to be informed about how to address atypical cases in the classroom.

Another practical implication of this study is addressed to the parent community. We consider that meetings are needed with parents and students, organized by the teacher, in which to discuss openly the issue of discrimination, labeling and segregation of children. Parents should contribute to the education of their children by promoting the ideas of non-discrimination, acceptance of diversity and offering and receiving help among children. Labeling is a painful but real phenomenon that occurs not only in atypical children, but also in those who come from disadvantaged backgrounds or who are of different ethnicities. Educating and informing parents by participating in discussion sessions with children and teachers would be a step forward in developing a peaceful and understanding community.

\section{Limitations and further research}

Given the sensible topic of the present study, there are a number of limitations that we aim to improve in our future research. First of all, the small number of participants should be mentioned. Our study involved 60 children with ASD from the Moldova region, which represents a very small percentage of the total number of officially diagnosed cases

\section{REFERENCES}

Bauminger, N., \& Kasari, C. (2000). Loneliness and friendship in high-functioning children with autism. Child Development, 71(2), 447-456.

Bluma, S., Shearer, M., Frohman, A., Hilliard, J. (1976). Portage guide to early education. Wisconsin: Portage Project.

Bourdieu, P. (1991). Language and symbolic power. Cambridge: Polity Press.

Britto, R. B. (2012). School Readiness: a conceptual framework. Retrieved on 10.08.2019 at: http://www.unicef.org/education/files/Chil2Child Conceptua IFramework_FINAL(1).pdf.

Bronfenbrenner, U. (1979). The ecology of human development: Experiments by nature and design. Massachusetts, USA: Harvard University Press.

Burrell, A., Bubb, S. (2000). Teacher feedback in the reception class: associations with children's pozitive adjustment to school. Education, 28(3), 58-69. of ASD. Another 60 children without developmental disorders were also invited to participate, randomly, from approximately the same classes (from the same schools). In our subsequent research efforts, we aim to make a broader analysis by attracting a larger number of participants with and without ASD in research.

Also, another limitation is the possible nuance of subjectivity of the parents who completed the questionnaires. In small localities, parents and teachers have closer relationships, while in cities the relations between them are more distant. This can interfere not only with the nature of the answers offered by parents, but even with the nature of teachers' behaviors and attitudes towards children. In subsequent studies we will consider the nature of the relationship between parents and teachers, the connection of parents with the school, but also the size of the residential areas of the families.

Another limitation could be that interpersonal relationships were reported by children. Although enough time was allocated for their interviews, and the items were adapted to their level of understanding, it is possible that the students provided desirable answers.

Another future direction of research, already implemented, is to follow longitudinally the evolution of these children. Some of them continue to be included in intensive ABA therapy programs, which facilitates the possibility of monitoring their long-term evolution.

Campbell Clark, S. (2000). Work/family border theory: A new theory of work/family balance. Human Relations, 53(6), 747770.

Dugan, E., Kamps, D., Leonard, B., Watkins, N., Rheinberger, A., \& Stackhaus, J. (1995). Effects of cooperative learning groups during social studies for students with autism and fourth grade peers. Journal of Applied Behavior Analysis, 28, 175 - 188.

Dunlop, A-W. A., Fabian, H. (eds.) (2003). Transitions. European Early Childhood Education Research Journal, Themed Monograph 1.

Eisenhower, A. S., Blacher, J., Bush, H. H. (2015). Longitudinal associations between externalizing problems and student-teacher relationship quality for young children with ASD. Research in Autism Spectrum Disorders, 9, 163-173. doi: 10.1016/j.rasd.2014.09.007

Elder, G. H. Jr. (2001). Families, social change, and individual lives. Marriage and Family Review, 31(1/2), 177192.

Fabian, H., Dunlop, A-W. A. (2002). Inter-connexions. Early Years Matters, vol. 2. Glasgow, Scotland: Learning and Teaching Scotland. 
Fabian, H., Dunlop, A-W. A. (2002). Children Starting School: A guide to successful transitions and transfers for teachers and assistants. London, UK: Routlege Falmer. Fabian, H., Dunlop, A-W. A. (2005). The importance of play in the transition to school. In J. R. Moyles (ed.), The excellence of play, second edition. Berkshire, UK: Open University Press/McGraw-Hill.

Fontil, L., Petrakos, H. H. (2015). Transition to school: The experiences of Canadian and immigrant families of children with autism spectrum disorders. Psychology in the Schools, 52, 773-788. Doi: 10.1002/pits.21859

Frederickson, N. L., \& Furnham, A. F. (1998). Sociometric classification methods in school peer groups: A comparative investigation. Journal of Child Psychology and Psychiatry, 39, 921-934.

Furrer, C., \& Skinner, E. A. (2003). Sense of relatedness as a factor in children's academic engagement and performance. Journal of Educational Psychology, 95, 148 162.

Gillham, J. E., Carter, A. S., Volkmar, F. R., \& Sparrow, S. S. (2000). Toward a developmental operational definition of autism. Journal of Autism and Developmental Disorders, 30, 269-278.

Gresham, F. M., \& Elliot, S. N. (1990). Social skills rating system manual. Circle Pines, MN: American Guidance Service.

Jordan, R. (2005). Autistic spectrum disorders. În A. Lewis \& B. Norwich (eds), Special teaching for special children?, pp. 110-22. Buckingham: Open University Press.

Katz, E., \& Girolametto, L. (2013). Peer-mediated intervention for preschoolers with ASD implemented in early childhood education settings. Topics in Early Childhood Special Education, 33(3), 133-143.

Kelly, A.B., Garnett, M.S., Attwood, T. et al. (2008). Autism Spectrum Symptomatology in Children: The Impact of Family and Peer Relationships. Journal of Abnormal Child Psychology, 36, 1069. https://doi.org/10.1007/s10802-008$\underline{\text { 9234-8 }}$

Kennedy, C. H. (2002). The maintenance of behavior change as an indicator of social validity. Behavior Modification, 26, 594-604.

Koegel, R., Kim, S., Koegel, L., \& Schwartzman, B. (2013). Improving socialization for high school students with ASD by using their preferred interests. Journal of Autism and Developmental Disorders, 43, 2121-2134.

Liss, M., Harel, B., Fein, D., Allen, D., Dunn, M., Feinstein, C., Morris, R., Waterhouse, L., Rapin, I. (2001). Predictors and correlates of adaptive functioning in children with developmental disorders. Journal of Autism and Developmental Disorders, 31(2), 219-230.
Little, L. (2002). Middle-class mothers' perceptions of peer and sibling victimization among children with Asperger's syndrome and nonverbal learning disorders. Issues in Comprehensive Pediatric Nursing, 24, 43-57.

Marsh, A., Spagnol, V., Grove, R., Eapen, V. (2017). Transition to school for children with autism spectrum disorder: A systematic review. World Journal of Psychiatry, 7(3), 184-196. doi: 10.5498/wjp.v7.i3.184

Moore, C. (2007). Speaking as a parent: thoughts about educational inclusion for autistic children. În R. Cigman (ed.), Included or Excluded? The Challenge of Mainstream for Some SEN Children, pp. 34-41. London: Routledge.

Norwich, B. \& Lewis, A. (2005). How specialised is teaching pupils with disabilities and difficulties? În A. Lewis \& B. Norwich (eds), Special Teaching for Special Children?, pp. 1-14. Buckingham: Open University Press.

Prino, L. E., Pasta, T., Giovanna, F., Gastaldi, M., Longobardi, C. (2016). The effect of autism spectrum disorders, down syndrome, specific learning disorders and hyperactivity and attention deficits on the studentteacher relationship. Electronic Journal of Research in Educational Psychology, 14, 89-106. doi: 10.14204/ejrep.38.15043

Sparapani, N., Morgan, L., Reinhardt, V. P., Schatschneider, C., Wetherby, A. M. (2016). Evaluation of Classroom Active Engagement in Elementary Students with Autism Spectrum Disorder. Journal of Autism and Developmental Disorders, 46, 782-796. doi: 10.1007/s10803-015-2615-2

Tager-Flusberg, H., \& Joseph, R. M. (2003). Identifying neurocognitive phenotypes in autism. Philosophical Transactions of the Royal Society B: Biological Sciences, 358, 303-314.

Thibaut, J. W., \& Kelley, H. H. (1959). The social Psychology of Groups. New York: Wiley.

UNESCO. (1994). The Salamanca statement and framework for action on special education. Paris: UNESCO. van Gennep, A. (1960). Rites of passage. London, UK: Routledge \& Kegan Paul.

Watkins, L., O'Reilly, M., Kuhn, M., Gevarter, C., Lancioni, G. E., Sigafoos, J., Lang, R. (2015). A Review of PeerMediated Social Interaction Interventions for Students with Autism in Inclusive Settings. Journal of Autism and Developmental Disorders. doi 10.1007/s10803-014-2264-x Whitney, I., Smith, P. K., \& Thompson, D. (1994). Bullying and children with special educational needs. În P. K. Smith \& S. Sharp (eds), School Bullying: Insights and Perspectives, pp. 213-240. London: Routledge.

Wing, L. (2007). Children with autistic spectrum disorders. În R. Cigman (ed.), Included or Excluded? The Challenge of Mainstream for Some SEN Children, pp. 23-33. London: Routledge. 